$$
\text { CONF- } 970711 \cdots
$$

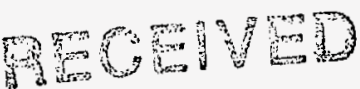 \\ PiA 25193

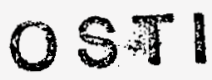

Author(s):

Robert C. Reedy, Richard D. Belian, Tom E. Cayton, Michael G. Henderson, John C. Ingraham, Jorg-Micha Jahn, Peter S. McLachlan, Mike M. Meier, Geoffrey D. Reeves, L.A. Weiss

Proceedings of the Conference on High-Energy Radiation Background in Space (Snowmass, CO; 22-25 July 1997) to be published in a IEEE Conference Record

\section{DISTRIBUTION OF THS DOCUMENT IS UNLIMITED!

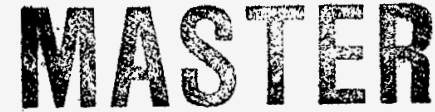

N

\section{Los Alamos}

\section{NATIONALLABORATORY}

Los Alamos National Laboratory, an affirmative action/equal opportunity employer, is operated by the University of California for the U.S. Department of Energy under contract W-7405-ENG-36. By acceptance of this article, the publisher recognizes that the U.S.

Government retains a nonexclusive, royalty-free license to publish or reproduce the published form of this contribution, or to allow others to do so, for U.S. Government purposes. Los Alamos National Laboratory requests that the publisher identify this article as work performed under the auspices of the U.S. Department of Energy. The Los Alamos National Laboratory strongly supports academic freedom and a researcher's right to publish; as an institution, however, the Laboratory does not endorse the viewpoint of a publication or guarantee its technical correctness. 


\section{DISCLAIMER}

This repor was prepared as an account of work sponsored by an agency of the United States Government. Neither the United States Government nor any agency thereof, nor any of their employees, makes any warranty, express or implied, or assumes any legal liability or responsibility for the accuracy, completeness, or usefulness of any information, apparatus, product, or process disclosed, or represents that its use would not infringe privately owned rights. Reference herein to any specific commercial product, process, or service by trade name, trademark, manufacturer, or otherwise does not necessarily constitute or imply its endorsement, recom. mendation, or favoring by the United States Government or any agency thereof. The views and opinions of authors expressed herein do not necessarily state or reflect those of the United States Government or any agency thereof. 


\title{
Long-Term Energetic-Particle Databases from Geosynchronous and GPS Orbits
}

\author{
R.C. Reedy ${ }^{1}$, R.D. Belian ${ }^{1}$, T.E. Cayton ${ }^{1}$, M.G. Henderson ${ }^{1}$, J.C. Ingraham ${ }^{1}$, \\ J.-M. Jahn ${ }^{1}$, P.S. McLachlan ${ }^{1}$, M.M. Meier ${ }^{1}$, G.D. Reeves ${ }^{1}$, and L.A. Weiss ${ }^{2}$ \\ ${ }^{1}$ MS D436 or ${ }^{2}$ B230, Los Alamos National Laboratory \\ Los Alamos, NM 87545 USA
}

\begin{abstract}
The Los Alamos National Laboratory has flown thirteen energetic-particle instruments on geosynchronous satellites since 1976 and on seven GPS satellites since 1983. These instruments measure electrons and protons over a wide range of energies. The various instruments and the particles and energies that they measure are described. The measured fluxes are stored at Los Alamos in several databases that are available to outside users.
\end{abstract}

\section{INTRODUCTION}

Energetic particles in space can induce serious radiation effects in spacecraft. Electrons with energies above about 10 $\mathrm{keV}$ can charge the surfaces and change the surface potential. Relativistic electrons (energies $>1 \mathrm{MeV}$ ) can penetrate deep into material and create hazardous deep dielectric charging. Discharges from surface charges built up by plasma particles are a well-known source of anomalies on spacecraft. High fluxes of solar energetic particles can create anomalies in electronics and degrade the performance of solar panels and other spacecraft components. A good knowledge of the temporal and spatial variations of these energetic particles is needed to determine the causes of spacecraft anomalies, to design future spacecraft and instruments, and to understand the space environment near the Earth as a function of time and location.

The Los Alamos National Laboratory has had energeticparticle instruments on thirteen spacecraft on geosynchronous satellites since 1976 and on seven satellites of the Global Positioning System (GPS) since 1983. Data from these and other instruments, such as plasma analyzers, have been sent to Los Alamos for processing and analysis and provide an extensive set of data on the fluxes of energetic particles at these orbits. Databases archiving the data from our instruments on geosynchronous or GPS satellites have been or are being established at Los Alamos and are described here. These continuous records are valuable for long-term studies of energetic particles in important regions of space near the Earth and often in studying the causes of radiation effects seen in spacecraft.

\section{Los Alamos ENERgETIC-PARTICle AND Plasma INSTRUMENTS}

\section{A. Geosynchronous Orbit}

The first Los Alamos energetic-particle instrument with a large database is the Charged Particle Analyzer (CPA) [1,2], which has flown on eight satellites at geosynchronous orbit (6.62 Earth radii, $R_{E}$ ) since 1976. CPA instruments on two satellites continue to generate data. The instrument consists of four subassemblies or units based on one or more semiconductor or scintillator detector elements. Each unit was designed for a specific particle (electron or proton) and energy range (low or high). The LoE electron unit has six nested energy levels (six different lower limits but the same upper limit) from 30 to $200 \mathrm{keV}$ with an upper threshold of $300 \mathrm{keV}$. The HiE electron unit has six nested energy levels from 0.2 to $1.4 \mathrm{MeV}$ with an upper-energy cutoff of 2.0 $\mathrm{MeV}$. The LoP proton unit has ten nested channels with a lowest threshold that varies among the different instruments in orbit between 0.07 to $0.15 \mathrm{MeV}$ and an upper threshold of $\sim 0.6 \mathrm{MeV}$. The HiP unit has 16 differential proton channels above $0.4 \mathrm{MeV}$ to $\sim 160 \mathrm{MeV}$.

In 1989, we began replacement of the CPA as the Los Alamos energetic-particle instrument on geosynchronous satellites with the Synchronous Orbit Particle Analyzer (SOPA). The SOPA instrument consists of three nearlyidentical two-element telescopes with $4 \mu \mathrm{m}$-front and 3000 $\mu \mathrm{m}$-rear silicon solid-state detectors [3]. The SOPA instruments have nine differential channels for electrons from $50 \mathrm{keV}$ to $1.5 \mathrm{MeV}$ and an integral electron channel above $1.5 \mathrm{MeV}$. It also has 12 differential channels for protons from $50 \mathrm{keV}$ to $50 \mathrm{MeV}$ and ten channels for particles heavier than protons (alpha particles to strontium). The SOPA instruments also perform dual-parameter pulse-height analysis of the output from the two detector elements. This extends the range of particle species to include ions of any mass that have sufficient energy to pass through the first element and to generate a signal in the back element. Data have been returned from SOPAs on five geosynchronous satellites. Only the electron and proton data are currently included in our databases. 
TABLE 1

LANL ENERGETIC-PARTICLE DATA FROM GEO AND GPS ORBITS

\begin{tabular}{|c|c|c|c|c|}
\hline Instrument & Years & Particle & Levels & Energies \\
\hline CPA-LoE & 1976- & Electrons & 6 & $30-300 \mathrm{keV}$ \\
\hline "LoP & & Protons & 10 & $-0.1-0.6 \mathrm{MeV}$ \\
\hline “ -HiE & “ & Electrons & 6 & $0.2-2 \mathrm{MeV}$ \\
\hline “-HiP & “ & Protons & 16 & $0.4-160 \mathrm{MeV}$ \\
\hline SOPA & 1989- & Electrons & 10 & $0.05->1.5 \mathrm{MeV}$ \\
\hline$"$ & " & Protons & 12 & $0.05-50 \mathrm{MeV}$ \\
\hline “ & “ & Heavy Ions & 10 & (varies) \\
\hline ESP & 1989- & Electrons & & $0.7-26 \mathrm{MeV}$ \\
\hline MPA & 1989- & Electrons & & $0.07-44 \mathrm{keV}$ \\
\hline BDD-I & $1983-92$ & Electrons & 4 & $0.5->4 \mathrm{MeV}$ \\
\hline BDD-II & 1990- & Electrons & $\begin{array}{l}4 \\
4 \\
4\end{array}$ & $0.2->5.9 \mathrm{MeV}$ \\
\hline BDD-IIR & 1998- & $\begin{array}{l}\text { Electrons } \\
\text { Protons }\end{array}$ & $\begin{array}{l}4 \\
8 \\
8\end{array}$ & $\begin{array}{l}0.08->5 \mathrm{MeV} \\
1.3->54 \mathrm{MeV}\end{array}$ \\
\hline
\end{tabular}

Higher-energy particles have been measured since 1989 using the Energy Spectrometer for Particles (ESP). The ESP is a bismuth germanate crystal coupled to a thick plastic scintillator that is coupled to a photomultiplier tube [4]. The ESP instrument can measure the spectrum of electrons from 0.7 to $26 \mathrm{MeV}$ and of protons from 11 to $>20 \mathrm{MeV}$.

Instruments to measure the electrons and ions associated with the plasma at geosynchronous orbit have also been on geosynchronous satellites since 1989. This plasma instrument, the Magnetospheric Plasma Analyzer (MPA) [5], measures electrons from $70 \mathrm{eV}$ to $44 \mathrm{keV}$ and ions from 90 $\mathrm{eV}$ to $43 \mathrm{keV}$. The MPA can be used to extend the measurements by the CPA or SOPA to lower energies and to study the behavior of the plasma in the vicinity of these spacecraft. The Los Alamos instrument at geosynchronous are summarized in Table 1 along with those on GPS satellites.

\section{B. GPS Satellites}

Some satellites of the Global Positioning System (GPS) carry a Burst Detector Dosimeter (BDD). The GPS satellites are in 12-hour circular orbits at $4.1 \mathrm{R}_{\mathrm{E}}$, which takes them into the heart of the trapped electron radiation belt four times per day. Two of the Block I GPS satellites, which were in a $63^{\circ}$-inclined orbit, carried a BDD-I instrument: Navstar-8 (NS08), which returned data from August 1983 until April 1984, and NS10, which returned data from October 1984 until November 1992. The BDD-I [6] consisted of silicon sensors under four domes. Holes in the domes allowed only a small fraction of the incident radiation to get inside the dome, where different filters gave four energy ranges. Electrons channels had lower thresholds of about $0.5,1.0,2.0$, and $4 \mathrm{MeV}$. Proton channels had lower thresholds of about 6, 10, 15, and $15.5 \mathrm{MeV}$.

On five Block II GPS satellites (in a $55^{\circ}$-inclined orbit), a BDD-I was or is being flown: NS18 (Feb. 90 - May 94), NS24 (Aug. 91 - present), NS28 (Apr. 92 - Oct. 96), NS33 (Apr. 96 - present), and NS39 (July 93 - present). The BDD-
II consists of two sensor assemblies, one under a solid dome and one with 15 holes [7]. The active sensor part has nested pairs of scintillators each viewed by a microchannel plate photomultiplier tube. The BDD-II has seven electron channels from 0.2 to $>5.9 \mathrm{MeV}$ and four proton channels from 9 to $>50 \mathrm{MeV}$. Three GPS satellites launched from 1998 until about 2000 as part of GPS Block IIR will include a new version of the BDD, the BDD-IIR. Later GPS satellites of Block IIR and then Block IIF will carry a Combined X-ray Dosimeter instrument, which will continue our coverage of energetic particles at GPS orbits to well into the next century.

The BDD data are stored in on-board memory and downlinked once per day during routine contact with the satellite. The ground station formats the BDD data into an EPRO (End PROduct) file that comes to Los Alamos over a network.

\section{LoS ALAMos ENERgETIC-PARTICLE DATABASES}

The energetic-particle data since 1979 from the CPA and SOPA instruments on geosynchronous satellites have been incorporated in a publicly-accessible database at Los Alamos. This digital database is stored on-line using a SUN workstation and 31 GB (as of October 1997) of hard disk storage [8,9]. The workstation is leadbelly.lanl.gov, with the internet node number 128.165.207.108. A single data file is stored for each satellite for each day. This database is on the "World Wide Web" (WWW) [8,9] with the "home page" http://leadbelly.lanl.gov/lanl_ep_data/anl_ep.html and includes the energetic-particle fluxes and supplementary information, such as how to use the database. The plasma data from the MPA instruments for the same period can be accessed from this site. This energetic-particle database is being expanded and is used as part of the International Solar Terrestrial Physics program for studies using many satellites in various orbits and as part of the National Space Weather Program to understand the space environment around the Earth. In addition, the data is supplied to the U.S. Air Force's Space Weather Forecasting Center for their use.

We are in the process of putting real-time displays of the SOPA data on the WWW. This product should be available late in 1997 and will be accessible through our energeticparticle home page on leadbelly.

The energetic-particle data from the BDD instruments on GPS satellites are being compiled into another database. At Los Alamos, the BDD EPROs (End PROducts) are unpacked, converted to counting rates, and written as ASCII files, one file per satellite per GPS-week (a new GPS-week begins at 00:00 UT each Sunday). Time, geographic coordinates, and a set of geomagnetic coordinates computed from the Tsyganenko-89-model field [10] are appended to the energeticparticle data to aid the interpretation of the measurements 
from the 4.1-R $\mathrm{R}_{\mathrm{E}}$, circular GPS orbit. Requests for energeticparticle data from the BDD instruments on GPS satellites should be directed to tcayton@lanl.gov.

Many studies have been and can be done using these databases. There have been over 200 publications using our CPA and SOPA data alone. For example, fluxes of relativistic electrons measured since 1979 showed that their fluxes varied with a cycle of about 10.5 years but out of phase with the sunspot cycle (having higher fluxes near periods of minimum solar activity) [11]. The large solar particle events in 1989 were studied using data from CPA instruments [12]. Combining data from geosynchronous orbit with those from other orbits, such as GPS, is helping researchers to understand the dynamics of energetic particles in the Earth's magnetosphere. With these databases coming "on line," others now can use them in their studies of energetic radiations in the Earth's environment.

\section{ACKNOWLEDGMENTS}

This work was support by the DOE and NASA and done under the auspices of the U.S. Dept. of Energy. We thank the many engineers, scientific programmers, and technicians at Los Alamos who helped to design, build, and calibrate these instruments and who handled the data from them.

\section{REFERENCES}

[1] P.R. Higbie et al., "High resolution energetic particle measurements at $6.6 \mathrm{Re}, 1$, electron micropulsations," $J$. Geophys. Res., Vol. 83, pp. 4851-4855, 1978.

[2] D.N. Baker et al., "High-energy magnetospheric protons and their dependence on geomagnetic and interplanetary conditions," J. Geophys. Res., Vol. 84, pp. 7138-7154, 1979.

[3] R.D. Belian et al., "High-Z energetic particles at geosynchronous orbit during the great solar proton event series of October 1989," J. Geophys. Res., Vol. 97, pp. 16897-16906, 1992.
[4] M.M. Meier et al., "The Energy Spectrometer for Particles (ESP): Instrument description and orbital performance," in Workshop on the Earth's Trapped Particle Environment. New York: Am. Inst. Phys. Conf. Proc. 383, 1996, pp. 203-210.

[5] D.J. McComas et al., "Magnetospheric Plasma Analyzer (MPA): Initial three-spacecraft observations from geosynchronous orbit," J. Geophys. Res., Vol. 98, pp. 13453-13465, 1993.

[6] D.M. Drake et al., "Experimental evaluation of the BDD-I dosimeter for the Global Positioning System," Nucl. Instrum. Methods Phys. Res., Vol. A333, pp. 571-588, 1993.

[7] W. Feldman et al., The BDD II: An improved electron dosimeter for the Global Position System. Los Alamos National Laboratory report LA-10453-MS, July 1985.

[8] G.D. Reeves et al., "Los Alamos geosynchronous space weather data for radiation belt modeling," in Radiation Belts: Models and Standards. Washington: Am. Geophys. Union Geophysical Monograph 97, 1996, pp. 237-240.

[9] G.D. Reeves et al., "Los Alamos space weather data products: On line and on time," in Proceedings of the Third International Conference on Substorms. European Space Agency report SP-389, pp. 689-694, 1996.

[10] N.A. Tsyganenko, "A magnetospheric magnetic model with a warped tail current sheet," Planet. Space Sci., Vol. 37, pp. 5-20, 1989.

[11] R.D. Belian et al., "Relativistic electrons in the outerzone: An 11 year cycle; Their relation to the solar wind," in Workshop on the Earth's Trapped Particle Environment. New York: Am. Inst. Phys. Conf. Proc. 383, 1996, pp. 13-18.

[12] G.D. Reeves et al., "The great solar energetic particle events of 1989 observed from geosynchronous orbit," $J$. Geophys. Res., Vol. 97, pp. 6219-6226, 1992. 


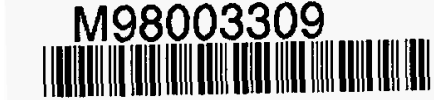

M98003309

CONF: $970711-46$

Publ. Date (11) 19980

Category (19) $\frac{D E / O D, X F}{4 C-700, D O E / E R}$

DOE 